\title{
The Relationship Between the Ratio of Interleukin-10(IL-10) and Tumor Necrosis Factor (TNF) with Plasmodium falciparum Density in Nigerian Children
}

\author{
Okoro Chinyere Ihuarulam ${ }^{1, ~ *, ~ A g o m o ~ C h i m e r e ~ O b i o r a ~}{ }^{2}$, Ihenetu Francis Chukwuebuka ${ }^{3}$, \\ Iroegbu Uchechi Francis ${ }^{4}$, Odinaka Kelechi Kenneth ${ }^{4}$, Nnadozie Raymond Ikechukwu ${ }^{5}$, \\ Dunga Kingsly Excell ${ }^{6}$, Okoro Oluchi Ijeoma ${ }^{7}$
}

${ }^{1}$ Department of Microbiology/Parasitology, Federal Medical Center, Owerri, Nigeria
2Department of Medical Laboratory Science, University of Lagos, Lagos, Nigeria
${ }^{3}$ Department of Microbiology, Federal University of Technology, Owerri, Nigeria
${ }^{4}$ Department of Paediatrics, Federal Medical Center, Owerri, Nigeria
${ }^{5}$ Department of Biology, Federal University of Technology, Owerri, Nigeria
${ }^{6}$ Department of Medical Laboratory Science, Madonna University, Elele, Nigeria
${ }^{7}$ Department of Microbiology, Beulah Medical Diagnostics and Research, Owerri, Nigeria

Email address:

ihuarulam2002@yahoo.com (O. C. Ihuarulam)

${ }^{*}$ Corresponding author

To cite this article:

Okoro Chinyere Ihuarulam, Agomo Chimere Obiora, Ihenetu Francis Chukwuebuka, Iroegbu Uchechi Francis, Odinaka Kelechi Kenneth, Nnadozie Raymond Ikechukwu, Dunga Kingsly Excell, Okoro Oluchi Ijeoma. The Relationship Between the Ratio of Interleukin-10(IL-10) and Tumor Necrosis Factor (TNF) with Plasmodium falciparum Density in Nigerian Children. European Journal of Preventive Medicine. Vol. 6, No. 4, 2018, pp. 58-63. doi: 10.11648/j.ejpm.20180604.14

Received: July 18, 2018; Accepted: August 20, 2018; Published: October 8, 2018

\begin{abstract}
Circulating levels of Tumour Necrosis Factor (TNF)- $\alpha$ have been shown to correlate with disease severity in African children. Interleukin 10 (IL-10) production appears to be important in the induction and maintenance of immunity to $P$. falciparum in naturally exposed populations.TNF- $\alpha$ induces fever, and elevated body temperatures can suppress parasitemia. Although TNF- $\alpha$-induced mechanisms can serve the host to control infection, prolonged exposure to TNF- $\alpha$ may adversely affect the individual by inducing or promoting severe disease. The present study was conducted among children in Imo State, South Eastern Nigeria between July 2014 and March 2015, with a view to assessing the relationship between Plasmodium falciparum density and the ratio of inter-leukin 10(IL-10) and tumor necrosis factor (TNF- $\alpha$ ). Blood samples were taken from children aged 1-72 months with fever or history of fever in the last 24 hours whose caregivers consented to the study.Malaria parasite density was determined by microscopy while the serum and/or plasma levels of cytokine by ELISA method.The geometric mean of IL-10/TNF- $\alpha$ ratios of $1.9 \mathrm{pg} / \mathrm{ml}, 2.0 \mathrm{pg} / \mathrm{ml}$ and $1.3 \mathrm{pg} / \mathrm{ml}$ were recorded for parasite density groups of 1$1000,1001-10000$ and $>10,000$ parasites/ $\mu$ lrespectively. IL-10/TNF- $\alpha$ ratio significantly decreased at high parasite density group $(>10,000$ parasites $/ \mu$ l) compared to lower parasite density groups $(\mathrm{p}=0.008)$. The IL-10/TNF $\alpha$ ratio in parasitized and healthy control groups were $3.4 \mathrm{pg} / \mathrm{ml}$ and $1.8 \mathrm{pg} / \mathrm{ml}$, respectively $(\mathrm{P}<0.05)$. Although significant increases in concentrations of IL-10 and TNF- $\alpha$ were observed among parasitized children compared to healthy controls, the reduction in IL-10/TNF- $\alpha$ among parasitized individuals suggests a much larger increase in the concentration of TNF- $\alpha$ compared to IL-10 in response to the presence of malaria parasites. Among parasitized children, IL-10/TNF- $\alpha$ ratio decreased as parasite density increased. Thus, IL-10/TNF- $\alpha$ ration may be a marker of severity of malaria infection among Nigerian children.
\end{abstract}

Keywords: Tumor Necrosis Factor (TNF- $\alpha$ ), Interleukin 10(IL-10), Malaria Parasite Density, IL-10/TNF- $\alpha$ Ratio 


\section{Introduction}

Malaria has played an important role in the history of mankind because it is a constant threat to human health and it affects economic development and growth in areas highly affected by the disease. Most of The disease is more lethal in children 0-5years, pregnant women and in people from nonmalaria endemic areas. Most of the clinical signs of malaria are caused by the parasite at stages in which it multiplies asexually in red blood cells. P. falciparum infection is most severe in children. However, only a small proportion of infected children develop severe complications; in nonimmune individuals malaria can cause severe and lifethreatening disease. Monokines and lymphokines are crucial for induction of immune effector mechanisms against many pathogens. The outcome of an infection appears to hinge on a delicate balance between appropriate and inappropriate induction of these inflammatory/anti-inflammatory mediators [1]. Nevertheless, excessive release of pro-inflammatory cytokines during a Plasmodium falciparum infection is reported to be the primary driving force of severe disease and eventual death [2-5].Importantly, down regulation of TNF- $\alpha$ production and consequent resistance to severe malaria, has been linked to the ability to produce the immuno-regulatory cytokine (IL-10) and Transforming Growth Factor (TGF)- $\beta$.A relative deficiency in immuno-regulatory cytokine (IL-10) and lower ratios of IL-10 to TNF- $\alpha$ has been recorded in patients with severe malaria. High ratios of IL-10 or TGF- $\beta$ to TNF- $\alpha$ have been also associated with decreased risk of malaria infection.

Monocytes and macrophages produce both cytokines and the speculation is that IL-10 may be produced soon after the production of TNF- $\alpha$ to regulate the inflammatory activities of TNF- $\alpha$. TNF- $\alpha$ induces fever, and elevated body temperatures can suppress parasitemia. In their review Iñigoet al. [6] reported that several previous studies have accumulated evidences which somewhat modified their perception of malaria and the role played by the immune system both in protection and pathogenesis and they advocated that routine detection of some of the cytokines may be relevant to diagnosis and prognosis of the various clinical conditions that might have distinguishable immunological features. The plasma IL-10/TNF- $\alpha$ ratio has been shown to be indicative of malarial complications [7, 8].Therefore, possible associations of the IL-10/TNF ratio with parasite density in children with uncomplicated malaria, and healthy controls were determined.

\section{Materials and Method}

\subsection{Study Area}

Children aged $1-72$ months were recruited from pediatric clinics in randomly selected private and public health facilities in Owerri Imo State in southeast Nigeria.This hospital based cross sectional descriptive study was conducted between the months of July 2014 and March,
2015. The climate of Imo State is essentially tropical with very high temperature within the months of November to March and seasonal rainfall. Two seasons are prominent in the State, namely rainy and dry seasons. The dry season starts in November and lasts until March while rainy season starts in April and ends in October. The mean monthly temperature of Imo State during the dry season is $34^{\circ} \mathrm{C}$ while it is $30^{\circ} \mathrm{C}$ in rainy season. It has relative humidity of about $60-80 \%$ throughout the year with a mean annual rainfall of 2000 to 2500 millimeters. The Parasitology unit of Federal Medical Center, Owerri served as slide reading Reference Laboratory because of the presence of a competent WHO -certified malaria expert microscopist.

\subsection{Enrolment of Study Participants}

Children between 1 and 72months of age with documented fever at presentation or history of fever in the last 24 hours but without any sign of severe malaria, hyperparasitaemia ( $>$ 250000 parasites $/ \mu \mathrm{L}$ ) or severe anaemia (haemoglobin level below $8.0 \mathrm{~g} / \mathrm{dls}$ ) and have not taken anti-malarial medicines were considered eligible. Fever was regarded as axillary temperature of $\geq 37.5^{\circ} \mathrm{C}$.For all subjects(febrile and afebrile), the presence of Plasmodium falciparum was assessed microscopically and with a malaria rapid diagnostic kit while history of fever, age,sex were documented using a semi-structured questionnaire. Each eligible child was enrolled after informed consent was obtained from their parent/Guardian. Ethical approval to conduct this study was obtained from the Ethical committee of Federal Medical Center Owerri, Imo state.The study was conducted in accordance with Good Clinical Practice (GCP) and Good Clinical Laboratory Practices (GCLPs)

\subsection{Sample Collection \& Parasitological Diagnosis of Malaria Parasitaemia}

Blood samples were collected after clinical examination by the managing physician and demographic data, from eligible study participants who consented to the study. Blood samples were dispensed into EDTA and plain vacutainer tubes, $3 \mathrm{mls}$ and $2 \mathrm{mls}$ respectively. Malaria blood smears were made using whole blood (EDTA), stained with 3\% Geimsa stain and examined with x100 objective. The parasite density was determined as the number of parasites per 500 leucocytes on a thick film and this was calculated as parasites per microlitre of blood assuming an average Leucocyte count of 8000 per $\mu \mathrm{l}$ of blood $[9,10]$. The parasite density of blood was expressed as:

$$
\text { Parasite density per } \mu \text { l of blood }=\frac{\text { No of Parasite counted X } 8000}{\text { No of Leucocytes counted }}
$$

The thin films were used to morphologically identify thePlasmodium species. Stained slides were examined under the light microscope using the $\mathrm{x} 100$ objective lens (immersion oil). A slide was considered negative after 100 high power fields (HPF) have been examined.Each slide was 
examined by experienced malaria Microscopist and any discordance in readings was resolved by a tie breaker (WHO certified expert malaria Microscopist).Acceptable discrepancy between two parasite counts wasset at $20 \%$ and the mean of the count were taken as the true count.

\subsection{Cytokine Assay (IL-10, TNF)}

Plasmaof all randomly selected children(both TEST and CONTROL)were separated and frozen in aliquots of $100 \mu \mathrm{l}$ in cryoval tubes at $-20^{\circ} \mathrm{C}$ until they were used for cytokine assays. Plasma samples were tested for cytokine levels within 3 months of the sample collection. The assay was done following the manufacturer's manual. Concentrations of IL10 in plasma were measured using ELISA (PRO Kit for Human IL-10(MABTECH CODE 3430-IHP-2) U.S.A while Plasma TNF- $\alpha$ concentrations were measured using ELISA (HUMAN TNF-alpha ELISA development Kit (3510-IH-20) U.S.A. Limit of detection for TNF was: $13 \mathrm{pg} / \mathrm{ml}(\mathrm{pico}$ $\operatorname{gram} / \mathrm{ml}$ ) while IL-10 was $0.5 \mathrm{pg} / \mathrm{ml}$

\subsection{Data Analysis}

Data obtained were compared using the chi-square test with the SPSS statistical program. The parasite densities were stratified into 3groups: 1-1000, 1001-10,000, and $>10,000$ parasites $/ \mu 1$. All reported $P$ values were twosided and $P \leq 0.05$ was considered statistically significant.

\section{Results}

A total of 1344 and 29 children 0-72 months old were enrolled in the study as Test and Control groups, respectively. The overall prevalence of malaria among symptomatic children was $26.3 \%$. The mean age \pm SD of the Test group was $40.3 \pm 18.4$ months while that of Control was 58.0 \pm 8.2 . Also the mean body Temp \pm SD was $37.0 \pm 0.9$ and $36.3 \pm 0.4$ for Test and Control groups respectively.

The geometric mean parasite density of children positive by microscopy was 1764 parasites/ $\mu$ l of blood with a range of (12-220,000parsites/ $\mu$ l of blood). The children with parasitaemia of 1-1000 parasites / $\mu \mathrm{L}$ (Group 1), 1001-10,000 parasites $/ \mu \mathrm{L}$ (Group II) and $>10,000$ parasites $/ \mu \mathrm{L}$ (Group III) were $158(45.5 \%), 106(30.3 \%)$ and $84(24.2 \%)$ respectively. (Table 1)

Table 1. Profile of Study Participant.

\begin{tabular}{lll}
\hline Character & Test & Control \\
\hline $\begin{array}{l}\text { Number of participants } \\
\text { Sex }\end{array}$ & 1344 & 29 \\
M & $693(51.7 \%)$ & $15(51.7 \%)$ \\
F & $648(48.3 \%)$ & $14(48.3 \%)$ \\
Age (months) & & \\
Mean \pm SD & $40.3 \pm 18.4$ & $58.0 \pm 8.2$ \\
$1-24$ & $366(27.2 \%)$ & 0 \\
$25-48$ & $420(32.2 \%)$ & $3(10.3 \%)$ \\
$48-72$ & $558(41.6 \%)$ & $26(89.7 \%)$ \\
Temperature $\left({ }^{\circ} \mathrm{C}\right)$ & & \\
Mean \pm SD & $37.0 \pm 0.9$ & $36.3 \pm 0.4$ \\
$<37.5$ & $955(71.1 \%)$ & $29(100 \%)$ \\
$\geq 37.5$ & $389(28.9 \%)$ & 0 \\
mRDT & & \\
Positive & $423(31.5 \%)$ & 0 \\
Negative & $921(68.5 \%)$ & $29(100 \%)$ \\
Microscopy & & \\
Positive & $353(26.3 \%)$ & 0 \\
Negative & $991(73.7 \%)$ & $29(100 \%)$ \\
Parasitaemia $(\mathrm{p} / \mu \mathrm{L})$ & $1764(12-220,000)$ & \\
Geomean $($ range $)$ & $158(45.5 \%)$ & \\
$1-1,000$ & $106(30.3 \%)$ & \\
$1,001-10,000$ & $84(24.2 \%)$ & \\
$>10,000$ & & \\
\hline
\end{tabular}

Sixty six children with uncomplicated malaria had higher IL-10 levels than TNF plasma levels and 29 of Control children had higher IL-10 than TNF plasma levels. The Geometric Mean of IL-10 of Test and Control groups were $270.5 \mathrm{pg} / \mathrm{ml}$ and $52.6 \mathrm{pg} / \mathrm{ml}$ respectively $(\mathrm{P}<0.001)$. The geometric mean of TNF- $\alpha$ of Test and Control groups were $153.4 \mathrm{pg} / \mathrm{ml}$ and $15.4 \mathrm{pg} / \mathrm{ml}$ respectively $(\mathrm{P}<0.001)$. The IL$10 /$ TNF $-\alpha$ ratio in the healthy control group was $3.4 \mathrm{pg} / \mathrm{ml}$ while that of symptomatic (Test) group was $1.8 \mathrm{pg} / \mathrm{ml}$. $(\mathrm{P}<0.001)$. (Table 2)

Table 2. IL-10 /TNF Ratios in Parasitized and Healthy Control Groups.

\begin{tabular}{|c|c|c|c|c|}
\hline STATUS & & IL-10 & TNF- $\alpha$ & IL-10/TNF- $\alpha$ \\
\hline \multirow{5}{*}{$\mathrm{HC}$} & $\mathrm{N}$ & 29 & 29 & 29 \\
\hline & Geometric Mean & 52.6 & 15.4 & 3.4 \\
\hline & Minimum & 20.9 & 8.9 & 1.2 \\
\hline & Maximum & 107.6 & 22.1 & 7.2 \\
\hline & $\mathrm{N}$ & 66 & 66 & 66 \\
\hline \multirow{2}{*}{ TEST } & Geometric Mean & 270.5 & 153.4 & 1.8 \\
\hline & Minimum & 35.9 & 14 & 0.7 \\
\hline \multirow{5}{*}{ Total } & $\mathrm{N}$ & 95 & 95 & 95 \\
\hline & Geometric Mean & 164.1 & 76.0 & 2.2 \\
\hline & Minimum & 20.9 & 8.9 & 0.7 \\
\hline & Maximum & 978 & 680 & 7.6 \\
\hline & $\mathrm{P}$ & $<0.001<$ & $<0.001$ & $<0.001$ \\
\hline
\end{tabular}

*Mann Whitney U Test P value; HC = Healthy control

There were significant associations $(\mathrm{P}<0.01)$ between Plasmodium falciparum parasitaemia and geometric means of IL-10, TNF- $\alpha$ and IL-10/TNF- $\alpha$ ratio in children infected with malaria. The cytokine ratio decreased from Geometric 
mean of $2.0 \mathrm{pg} / \mathrm{ml}$ in Density group of $1001-10000$ to 1.3 $\mathrm{pg} / \mathrm{ml}$ in $>10,000$ parasites $/ \mu$ l group. Higher parasitemic children had a higher IL-10 than TNF plasma level. In these individuals, IL-10/TNF plasma level ratios were significantly lower than in children with low or mid (meso) parasitemia (KruskalwallisP $=0.008$ ) as shown in Table 3:

Table 3. Association between Parasite Density and IL-10/TNF Ratio

\begin{tabular}{|c|c|c|c|c|}
\hline \multicolumn{2}{|c|}{ Parasitaemia (parasite/ $\mu \mathrm{l}$ ) } & \multirow{2}{*}{$\begin{array}{l}\text { IL-10 } \\
15\end{array}$} & \multirow{2}{*}{$\frac{\text { TNF- } \boldsymbol{\alpha}}{15}$} & \multirow{2}{*}{$\begin{array}{l}\text { IL-10/TNF-0 } \\
15\end{array}$} \\
\hline \multirow{4}{*}{$1-1000$} & $\mathrm{~N}$ & & & \\
\hline & $\begin{array}{l}\text { Geometric } \\
\text { Mean }\end{array}$ & 126.6 & 67.2 & 1.9 \\
\hline & Minimum & 35.9 & 19.2 & 1 \\
\hline & Maximum & 315 & 300.4 & 2.8 \\
\hline \multirow{5}{*}{$1001-10000$} & $\mathrm{~N}$ & 23 & 23 & 23 \\
\hline & $\begin{array}{l}\text { Geometric } \\
\text { Mean }\end{array}$ & 290.5 & 148.2 & 2.0 \\
\hline & Minimum & 84 & 48.2 & 0.8 \\
\hline & Maximum & 788 & 680 & 3.4 \\
\hline & $\mathrm{N}$ & 22 & 22 & 22 \\
\hline \multirow[t]{3}{*}{$>10000$} & $\begin{array}{l}\text { Geometric } \\
\text { Mean }\end{array}$ & 465.3 & 347.0 & 1.3 \\
\hline & Minimum & 278 & 99.2 & 0.7 \\
\hline & Maximum & 978 & 600 & 2.9 \\
\hline \multirow{5}{*}{ Total } & $\mathrm{N}$ & 60 & 60 & 60 \\
\hline & $\begin{array}{l}\text { Geometric } \\
\text { Mean }\end{array}$ & 280.5 & 166.1 & 1.7 \\
\hline & Minimum & 35.9 & 19.2 & 0.7 \\
\hline & Maximum & 978 & 680 & 3.4 \\
\hline & $\mathrm{P}^{*}$ & $<0.001$ & $<0.001$ & 0.008 \\
\hline
\end{tabular}

*Kruskalwallis P-value, N- No of subjects

All malaria positive children had elevated cytokine levels both in febrile and afebrile children. The geometric mean of
IL-10 and TNF- $\alpha$ in febrile parasitaemic children were 280.5 $\mathrm{pg} / \mathrm{ml}$ and $166.1 \mathrm{pg} / \mathrm{ml}$ respectively while it was $65.4 \mathrm{pg} / \mathrm{ml}$ and $19.9 \mathrm{pg} / \mathrm{ml}$ in febrile aparasitaemic children. The geometric mean of IL-10/TNFratios in parasitaemic versus aparasitaemic were $1.7 \mathrm{pg} / \mathrm{ml}$ vs $3.3 \mathrm{pg} / \mathrm{ml}$.There was therefore significant differences in cytokine levels in febrile malaria positive and febrile malaria negative children (Table 4).

Table 4. IL-10 /TNF Ratios in Febrile Parasitized and Febrile Non Parasitized Groups.

\begin{tabular}{lllll}
\hline \multicolumn{2}{l}{ Microscopy } & IL-10 & TNF $-\boldsymbol{\alpha}$ & IL-10/TNF $-\boldsymbol{\alpha}$ \\
\hline \multirow{4}{*}{ Pos } & N & 60 & 60 & 60 \\
& Geometric & 280.5 & 166.1 & 1.7 \\
& Mean & & & \\
& Minimum & 35.9 & 19.2 & 0.7 \\
& Maximum & 978.0 & 680.0 & 3.4 \\
& N & 35 & 35 & 35 \\
\multirow{4}{*}{ Neg } & Geometric & 65.4 & 19.9 & 3.3 \\
& Mean & & & \\
& Minimum & 20.9 & 8.9 & 1.2 \\
& Maximum & 452.2 & 298.0 & 7.6 \\
& N & 95 & 95 & 95 \\
\multirow{4}{*}{ Total } & Geometric & 164.1 & 76.0 & 2.2 \\
& Mean & & & \\
& Minimum & 20.9 & 8.9 & 0.7 \\
& Maximum & 978.0 & 680.0 & 7.6 \\
& P & $<0.001$ & $<0.001$ & $<0.001$ \\
\hline
\end{tabular}

Table 5 shows the significant association between overall body temperature and IL-10/TNF- $\alpha$ ratio $(\mathrm{P}=0.018)$. However, there was no association between body temperature and IL$10 /$ TNF- $\alpha$ ratio within the parasite density groups $(\mathrm{P}>0.05)$.

Table 5. Relationship Between Parasite Density, Body Temperature and IL-10:TNF- $\alpha$ Ratio.

\begin{tabular}{|c|c|c|c|c|c|c|}
\hline \multirow[b]{2}{*}{$\begin{array}{l}\text { parasite density } \\
\text { (parasites } / \mu \mathrm{l})\end{array}$} & \multirow[b]{2}{*}{$\begin{array}{l}\text { Body Temperature } \\
\left({ }^{\circ} \mathrm{C}\right)\end{array}$} & \multirow[b]{2}{*}{$\mathbf{N}$} & \multicolumn{3}{|l|}{ IL-10/TNF- $\alpha$} & \multirow[b]{2}{*}{$P^{*}$} \\
\hline & & & Geometric Mean & Minimum & Maximum & \\
\hline \multirow{3}{*}{$1-1000$} & $<37.5$ & 9 & 2.147 & 1.1 & 2.8 & \multirow{3}{*}{0.181} \\
\hline & $>=37.5$ & 6 & 1.523 & 1.0 & 2.7 & \\
\hline & Total & 15 & 1.871 & 1.0 & 2.8 & \\
\hline \multirow{3}{*}{$1001-10000$} & $<37.5$ & 15 & 1.821 & 0.8 & 3.4 & \multirow{3}{*}{0.506} \\
\hline & $>=37.5$ & 8 & 2.225 & 1.5 & 3.3 & \\
\hline & Total & 23 & 1.952 & 0.8 & 3.4 & \\
\hline \multirow{3}{*}{$>10000$} & $<37.5$ & 14 & 1.227 & 0.7 & 2.7 & \multirow{3}{*}{0.165} \\
\hline & $>=37.5$ & 8 & 1.557 & 0.7 & 2.9 & \\
\hline & Total & 22 & 1.338 & 0.7 & 2.9 & \\
\hline \multirow{3}{*}{ Total } & $<37.5$ & 38 & 1.637 & 0.7 & 3.4 & \multirow{3}{*}{0.018} \\
\hline & $>=37.5$ & 22 & 1.762 & 0.7 & 3.3 & \\
\hline & Total & 60 & 1.682 & 0.7 & 3.4 & \\
\hline
\end{tabular}

*Mann Whitney U test

\section{Discussion}

The present study shows $26.3 \%$ prevalence of malaria parasites by microscopy. The anti-inflammatory cytokine IL10 is secreted simultaneously or shortly after the proinflammatory cytokine TNF- $\alpha$ and IL-10 inhibits the release of TNF- $\alpha$ [12]. This may explain the finding of increase in levels of both cytokines with increase in parasitaemia. Type 1 cytokines are important in controlling early parasitemia, although they need to be counterbalanced later in the infection by a type 2 response which leads to antibody production. Also the pathogenesis of malaria is a complex process in which a common outcome might be reached by different routes [6].

Dodoo et al. [11] suggested that studying ratios between pro- and anti-inflammatory cytokines for the prognosis of parasite killing might add more information to what cytokine profiles are beneficial or detrimental. TNF- $\alpha$ induces fever, and elevated body temperatures can suppress parasitemia. 
While such TNF- $\alpha$-induced mechanisms can serve the host to control infection, prolonged exposure to $\mathrm{TNF}-\alpha$ may adversely affect the individual by inducing or promoting severe disease. Induction of high IL-10 production might be a direct or indirect mechanism whereby the parasite evades the immune response [12]. The parasite might 'deliberately' enhance the IL-10 production in order to interfere with the balance between pro-and anti-inflammatory immune reactions to escape effective parasite killing [12].Lutyet al.[13] described a positive association between serum IL-10 level and parasite density in symptomatic P.falciparum malaria (before start of treatment).Hugosson et al.[12] also found associations between initial IL-10 levels and parasite densities during treatment, indicating that the IL-10 levels may play a role in the clearance of parasites during treatment. By adjusting for temperature, treatment, age and sex Hugosson et al. [12] demonstrated that such adjustment even enhanced the association between IL-10 level and the risk of having higher parasite density at 24 hours. This study therefore agrees with Hugosson et al.[12];lutyet al. [13] and a study in Gabon children where a significant association between IL-10 levels and parasite density was observed $(\mathrm{P}<$ $0.00001)$ [14].

In a previous study hyperparasitaemia was associated with higher ratios of IL-10/TNF- $\alpha$ plasma levels in children with severe malaria [15]. In this study, children with high parasitaemia uncomplicated malaria had higher IL-10 than TNF- $\alpha$ plasma level compared with low and mid parasite density uncomplicated malaria groups. More so the IL-10/TNF- $\alpha$ plasma level ratios of children with high falciparum parasite density were significantly lower (IL-10/TNF- $\alpha<1$ ) than the low and mid parasite density uncomplicated malaria groups.This agrees with other reports that high ratio of IL-10/TNF- $\alpha$ is implicated in low parasite density are positively associated with decreased risk of malaria infection. Thus a significant relationship was observed between parasite density and IL-10/ TNF- $\alpha$ ratio.

Interestingly, children with fever and detectable parasitemia, and not afebrile parasitized patients, had elevated levels of TNF- $\alpha$ and this is in agreement with study by McGuireet al. [16].The low IL-10:/TNF $-\alpha$ plasma level ratios in this study suggests the inability of some children to mount up adequate anti-inflammatory cytokine before start of treatment and this resulted to increased parasite density in the subjects.

\subsection{Conclusion}

Significant increases in levels of IL-10 and TNF- $\alpha$ were observed among parasitized children compared to healthy controls,however,the IL-10/TNF-aratio was lower in parasitized children. This finding suggests that higher levels of TNF- $\alpha$ than IL-10 are produced in response to malaria infection. Among parasitized children, IL-10/TNF- $\alpha$ ratio appeared decreased with increase in parasitaemia. Thus, IL$10 /$ TNF- $\alpha$ ratio may be a marker of severity of malaria infection among Nigerian children.

\subsection{Recommendations}

Blood samples for cytokine determination were collected only on day 0 and were only assayed once before start of treatment.Blood sample collection on day1, 2 and day 3 after commencement of treatment is being advocated for a better understanding of possible role played by IL-10/TNF- $\alpha$ ratio in falciparum parasite clearance and fever reduction in children from the south eastern Nigeria.

\section{References}

[1] Omer SA, Idress HE, Adam I, Abdelrahim M, Noureldein AN Abdelrazig AM, Elhassan MO, SulaimanSM. Malar J. 2017 Sep 16;16(1):374.

[2] Spriggs DR, Sherman ML, Kufe DW, Frei E: Tumor necrosis factor: clinical trials and future directions, TumourNecrosis Factor and Related Cytotoxins. Ciba Foundation Symposium No. 131. 1998 Edited by G Bock, J Whelan, J Marsh. New York, John Wiley and Sons (In press)

[3] Kremsner P G, Neifer S, Chaves MF, Rudolph R, Bienzle U. Interferon-gammainduced lethality in the late phase of Plasmodium vinckei malaria despite effective parasiteclearance by chloroquine. European Journal of Immunology, 1992. 22, 2873-8.

[4] Waki S, Uehara S, Kanbe K, Ono, K, Suzuki M, Nariuchi H. The role of $\mathrm{T}$ cells in pathogenesis and protective immunity to murine malaria. Immunology, 1992. 75, 646-651.

[5] Jacobs-Lorena, M. and Oo, M-M. The peritrophic matrix of insects. in: B.J. Beaty, W. Marquardt (Eds.) The Biology of Disease Vectors. University Press of Colorado, 1996: 318-332

[6] Iñigo Angulo1 and Manuel FresnoCytokines in the Pathogenesis of and Protection against MalariaClin Vaccine Immunol November 2002 vol. 9 no. 6 1145-1152

[7] Kurtzhals JA, Adabayeri V, Goka BQ, et al. Low plasma concentrations of interleukin 10 in severe malarial anaemia compared with cerebral and uncomplicated malaria. Lancet 1998; 351: $1768-1772$.

[8] Othoro C, Lal AA, Nahlen B, Koech D, Orago AS \&Udhayakumar V. A low interleukin-10 tumor necrosis factor-alpha ratio is associated with malaria anemia in children residing in a holoendemic malaria region in western Kenya. J InfectDis 1999; 179: 279 - 282.

[9] Cheesbrough M. Biochemical tests to identify bacteria. In: Laboratory practice in tropical countries, Cambridge edn. 2002. pp. 36-70.

[10] WHO. Basic malaria microscopy, Part 1. Learner's guide second edition. Geneva: World Health Organization 2010(http://whqlibdoc.who.int/publications).

[11] Dodoo D, Omer FM, Todd J, Akanmori BD, Koram KA \& Riley EM. Absolute levels and ratios of pro-inflammatory and anti-inflammatory cytokine production in vitro predict clinical immunity to Plasmodium falciparum malaria. J Infect Dis 2002;185: $971-979$

[12] Hugosson, E., Montgomery, S., Premji, Z., Troye-Blomberg, M., Bjorkman, A. Higher IL-10 levels are associated with less effective clearance of Plasmodium falciparum parasites. ParasiteImmunology, 2004; 26(3), 111-117. 
[13] luty AJ, Perkins DJ, Lell B, et al.Low interleukin-12 activity in severe Plasmodium falciparum malaria. Infect Immun 2000; 68: $3909-3915$.

[14] Sandrine LydieOyegue-Liabagui, AlineGaëlleBouopdaTuedom, Lady CharlèneKouna, Sydney Maghendji-Nzondo, Herman Nzoughe, Nina Tchitoula-Makaya, Irene PeghaMoukandja, and Jean-Bernard Lekana-DoukiPro- and antiinflammatory cytokines in children with malaria in Franceville, GabonAm J ClinExpImmunol.2017; 6(2): 9-20.
[15] May J, Falusi AG, MockenhauptFP.Impact of subpatent multi - species and multi - clonal plasmodial infections on anaemia in children from Nigeria. Transactions of the Royal Society of Tropical Medicine and Hygiene2000; 94, 399-403.

[16] McGuire, W., U. D'Alessandro, S. Stephens, B. O. Olaleye, P. Langerock, B. M. Greenwood, and D. Kwiatkowski.1998. Levels of tumour necrosis factor and soluble TNF receptors during malaria fever episodes in the community. Trans. R. Soc. Trop. Med. Hyg.92:50-5. 